GUEST EDITORIAL

\title{
GOLDEN ERA FOR REHABILITATION SCIENCES WITH ENORMOUS CHALLENGES
}

Education in rehabilitation sciences have seen a boom in the last two decades in Pakistan and a variety of undergraduate and postgraduate courses have been introduced in the country. Up gradation of BS physical therapy into DPT program, BS Occupational Therapy into Doctor of Occupational Therapy, introduction of BS programs in Allied Health Sciences including Speech and Language pathology, Respiratory therapy, prosthetics and orthotics are glimpses of development of rehabilitation sciences in the country.

Moreover, establishment of new rehabilitation centers have increased in number and a variety of patients with different rehabilitation needs'. These new centers might be helpful to fulfill the potential upcoming demand and competition for quality in healthcare services in the country. It seems plausible that with enhanced skills of the professionals produced in the field of rehabilitation, the demand of consumers for having best quality will raise and sooner the need of having set national standards for these professions will be realized by the concerned authorities. At the moment, the authorities seem least interested in the formation of regularity bodies for individual profession.

Meanwhile, an effort to have a combined regularity body for some of the specialties has been initiated by the government along with the collaboration of Higher Education Commission, Pakistan. This step seems a milestone towards setting standards for these professions; however, 'one-size-fits-for-all' may not be a good solution for setting the standards. Despite the fact that rehabilitation members of multiple specialties are working very closely with each other's area of expertise, still, each domain of rehabilitation sciences is unique and has got different dynamics. Setting general standards for all these different professions might be an easy task; nevertheless, each specialty requires its specific standards. This means that specific standards should be set and approved by all concerned authorities who have a major contribution from personnel who have deep insight into the profession.

Another raising concern about these professions in Pakistan is uncontrolled growth of organizations offering graduate programs in these specialized courses. Less than two decades ago, the number of schools offering BS programs in rehabilitation sciences was less than two digits ${ }^{2}$. However, with up gradation of some of the programs, an alarming increase in number of these schools is observed in the country. At the moment, more than hundred schools are offering BS programs in rehabilitation sciences in the country.

These schools have brought boom in the education business and more people are investing in it. No doubt education and health are two revenue generating businesses, yet, low standards, lack of professional accountability and poor quality remains some of the high risks ${ }^{3}$. This seems an inherent problem associated with the increasing number of institutes offering BS programs in rehabilitation sciences in Pakistan. These institutes are often run by inexperienced faculty with less academic and clinical exposures and as a result these graduates are unable with lack of basic knowledge and clinical skills are exposed to compete the demand for quality in health services.

Another important issue with rehabilitation sciences in our country is unavailability of tailor-made curricula in these specialties. Most of the time, curriculum for these programs are adopted from developed countries where the dynamics of rehabilitation is completely different from rehabilitation in our country. This might be acceptable at the time of launching these courses; however, content needs to be revised by an expert's opinion to fulfill the demands of modern era.

How a country where access to basic needs is not available for all its population can exactly follow curricula designed for rehabilitation in developed countries? It is really important to have accreditation of our degrees in other countries; however, this may not be achieved on the cost of ignoring the requirements, needs and demands of our community.

\section{Dr. Haider Darain}

PhD (Edinburgh, UK), MSc, BSPT

Director Institute of Physical Medicine and Rehabilitation

Khyber Medical University, Peshawar 


\section{REFERENCES}

[1] Rathore FA, New PW, Iftikhar A. A report on disability and rehabilitation medicine in Pakistan: past, present, and future directions. Arch Phys Med Rehab. 201 1;92(1):161-6

[2] Ahmad A. Earthquake 2005-Spinal Cord Injury Rehabilitation in Pakistan. Adv Clin Neurosci Rehabil. 2008;8(4):18-19

[3] Babur MN, Siddique FR, Awan WA. Future of physical therapy in Pakistan-Satisfaction amongst Pakistani physical therapists about their profession. IMJ. 2014;6(1):25-7 